\title{
Dialectal Peculiarities of Indian Text and Context in Translation Practice: A Critique
}

DEEPA KUMAWAT

B. K. ANJANA

\begin{abstract}
Translation from one language to another is a continual phenomenon but when translation takes place between regional literary texts and English, it tends to call certain translational choices at two levels. On the first level, to decipher out the nuances of the original, the translator has to delve deep to know more than what is written on linguistic level in the original and then the possible effective expression of it into the TL follows on the other level. The present paper analyses the same exemplifying the short stories of Maitreyi Pushpa, a Hindi author, who writes in dialectal variation of Hindi pertinent to the region where the stories have been set. Maitreyi Pushpa's fondness of using the varieties and derivations of kinship terms, reduplicated forms and compound words, regional cultural rituals and other specific lexical peculiarities etc. have been analysed in the process of translation and it is found that the conflict for finding the closest possible equivalents rather needs some integrated approach to analyse it in the cultural context and situation. Looking at the ideological and thematic details of Indian literary texts, it has also been found that translations bring forth the Indian perspectives and landscape of these widely discussed ideologies viz. the grim face of Indian feminism in Pushpa's writings.
\end{abstract}

Keywords: Dialectal Variety, Context, Indian Literature, Maitreyi Pushpa, Translation. 


\section{I}

Dialectal variations of a language in a literary work, when to be translated, first include its best comprehension in its standard variety and then it possibly paves the way to take translational decision depending upon the culture and context of the particular setting in which the literary world is explored by its original author. In this way, we can safely assume that language is not at all a barrier if one really wants to communicate. Franz Boas, one of the fathers of modern anthropology discusses the link between language, thought and (primitive) culture. He also felt that language was not itself a barrier to thought but there was a dynamic relationship between language, culture and thought (qtd. in David Katan 2004: 99). Boas (2013: 63) in his Handbook of American Indian Languages accepts "the form of language will be moulded by the state of that culture." In the process of translation, an intuitive interpretation of the SL text and its dissemination in the TL text is fundamental. Texts belong to a multilingual society or culture like in Indian regional literature, when translated, double this need. In regional varieties of the same language, there are varieties of contexts where the same culturally significant term might be found in a different form or connotation. At such juncture, the context, culture and situation of the SL text help to find the proper equivalent provided that the bilingual agency is able to comprehend it well. Malinowski, a Polish author coined the term 'context of situation' and 'context of culture' and noted that a language could only be fully understood, i.e. have meaning, when these two contexts (situation and culture) were implicitly or explicitly clear to the interlocutors (qtd. in Gunter Senft et al. 2009: 111). Concerning the translation from Indian languages, Kashi Prasad (1982: 86) writes, "The translator has to catch the spirit of the original. What does the word spirit mean? The word appears to have become a cliché. It means breath, the 
vital force. It is not making contact with an individual writer but with an entire culture, with a value system. It is this spirit which is sought to be conveyed through translation". All these theoretical assumptions can be best experienced, despite agreements or a few denials, on the practical grounds. Hence, the second part of the paper tries to demonstrate how the presence of context, culture and regional flavours affect the process of translation and the subsequent strategies to follow.

\section{II}

The language of short stories of Maitreyi Pushpa (b. 1944), a Hindi author renowned for her candid depiction of rural women, is culturally engrossed with rural suburb of the particular region, the outskirts of the state of Uttar Pradesh to be precise. Since the stories represent very raw emotions, agonies and sufferings of the village women, they are mostly expressed in the regional and culture-bound diction and dialectal variations. Representing the bitter experiences of Indian rural women under patriarchal system, the themes depict the Indian version of feminism and so translation of the diction of the text remains a challenging and decisive journey throughout. Let us look at the different areas of vocabulary used in the stories and their respective translations. Illustrations are mostly drawn from the story "Lalmaniyan" (Pushpa 2005: 292-306) and some from other stories that have been mentioned in the paper.

\section{Kinship Terms and Non-consanguineous References}

What if an unknown to Hindi would be called as Bahin, Bahinji or as Dada, Dadda etc.? Certainly, either s/he might misunderstand or might ignore or suspect being called by such kinship terms. In most of the Indian languages, Indian diversity of calling different relations by different connotations is wellknown and the bulk of researchers in the field of Cultural studies and Translation Studies have theorized upon the same. 
However, one's knowledge of the "structure of kinship relationships are of assistance in the translation of kinship terms" (Abraham Rosman and Paula G. Rubel (2003: 276). The phenomenon becomes more complex when it relates to the villages of India where one might find substantial deviations from the standard dialects but as stated just above, the contextual references of the text often provide clues to comprehend it at source level and that pave the way for their translations. In the story "Lalmaniyan", for example, there are specific words to address elder or younger sister i.e. Jiji and the derivative Jijji in the story "Chinhar" (Pushpa 2015: 92). While now, in the urban culture, the elder sister is called as Didi, in the rural term the same becomes deviant as Jiji. Normally, the translation of "sister" (as bahan in Hindi) is assumed as one's biological sister but in the story Muskurati Aurtein (Pushpa 2015: 390), there are instances where women characters are addressed as Bahin or Bahinji (Pushpa 2015: 399) irrespective of any direct family or consanguineous relationship amongst them even in the farthest way. To translate these discreet lexical units into English needed a strategy and the best way found was to keep the original term transcription and give the meaning immediately in the parenthesis to get the rhythm of the text. As cultural transference takes place in the process of translation, these cultural nuances should also be carried through translation. Observing Henry Morgan, Abraham Rosman and Paula G. Rubel (2003: 269) analyses, "If people recognize that (kinship system) in their own culture the kin terms that they use form a system, they are better able to recognize such systems in other cultures that they become aware of the fact that these systems differ from their own". This befits in the TLT when readers are able to recognize the differences and mutual equivalency in the TL. 
Similarly, the accepted equivalent for "grand-father" in Hindi is Dada but in rural India one might call any of the old man of the village as Dada out of respect. However, the problem gets doubled when deliberately it remains on the tongues of the villagers to spell out it as Dadda or by the mark of paying reverence as Dadaji ( $\mathrm{J} i$ is put after the kinship terms to show reverence to the elders and it has become typical of the culture now as in the case of Bahinji mentioned above). There are cultural borrowings also that encroach into the regional languages; for example, though the stories are set in the villages of Bundelkhand (region of the middle India), the typical Sanskrit word jan-ni जननी (meaning 'mother') has been adopted by its far-evolved form as ja-nee जनी (Pushpa 2015: 293). In the story, "Lalmaniyan" the word finds expression to refer to any 'any woman' as in the sentence:

\section{"use koi dabang ja-nee naache toh..." (Pushpa 2015: 293).}

"if any strong women would dance, then... "(trans.).

In most of the cases the context of the situation and that particular culture prepare the translator to decide for the equivalent words and in some cases only possessive kinship hierarchies tell us the exact meaning of that relation; for example- sister's husband for Jija, husband's sister for Nanad, son-in-law for Damad etc. If a translator goes with the literal meaning of these dialectically varied kinship term/s, such diverse contexts of culture, situations might pose problems in translation, and so the comprehension of the context of the ST is crucial and inescapable in the process of translation. On the other hand, the semantic system of such kinship terminologies cannot be left without some translational decisions as "each kinship terminology has an internal logic of its own; when one element of the system changes, the rest of the system will 
change accordingly" (Abraham Rosman and Paula G. Rubel 2003: 269).

\section{Deep-rooted Cultural, Feminine Adornments and Clothing}

In India, being a land of varying cultural festivities, women dress and adore themselves on various occasions with various cosmetics and natural beautifiers. In the story "Lalmaniyan", there are a number of references to these beautifiers which are deeply culture-rooted and cause difficulties in translation. As Vladimir Ivir (1987: 38) in his essay, "Procedures and Strategies for the Translation of Culture" suggests to fill up these cultural gaps, the translation of these can only be taken into TT by paraphrasing them to maintain the rustic flavour of the SLT and their better comprehension to the readers of different culture/s. In this way, the non-Hindi and other readers can get the idea of the original cultural terms (while we transcribe it) and culture get transmitted through the translation/s.

A few instances from the story "Lalmaniyan" (Pushpa 2015: 292-306)

\begin{tabular}{|l|l|}
\hline SL Text Item/s & Possibility/ies of Translation and Paraphrasing \\
\hline Alta and mahavar & $\begin{array}{l}\text { The natural beautifier used by women to adorn } \\
\text { their palms, edges of the feet, tip of the finger etc } \\
\text { on various auspicious occasions. If it is simply } \\
\text { translated as a 'red liquid', it may baffle to the } \\
\text { readers in reckoning the meaning and the } \\
\text { continuity of story reading may get break. }\end{array}$ \\
\hline Bichhiya & $\begin{array}{l}\text { An ornament worn by married women in toes and } \\
\text { considered auspicious for various cultural reasons. } \\
\text { Translating it merely as 'toe ring' may wonder the } \\
\text { culturally unaware readers as why to 'wear' it. }\end{array}$ \\
\hline $\begin{array}{l}\text { Kajal } \\
\text { Soorma }\end{array}$ & $\begin{array}{l}\text { A typical Indian eye make-up worn by women to } \\
\text { beautify their eyes. The use of the word is } \\
\text { contextual where sometimes it is a sign of getting } \\
\text { rid of evil eyes or bad omen for newborn babies. } \\
\text { Hence, putting it as 'collyrium' (as the dictionaries }\end{array}$ \\
\hline
\end{tabular}




\begin{tabular}{|l|l|}
\hline Bindi and Tikuli & $\begin{array}{l}\text { Suggests) may deviate the contextual meaning. } \\
\text { seem rather odd and the readers may not get its } \\
\text { relevance. }\end{array}$ \\
\hline Seedha-pallu & $\begin{array}{l}\text { While Pallu can be simply translated as the corner } \\
\text { of the Sari (which is already an Indian attire), } \\
\text { there is no exact equivalent for Seedha-pallu and } \\
\text { hence paraphrasing remains the option i.e. a } \\
\text { particular style of wearing a Sari. }\end{array}$ \\
\hline Kurta-Pajama & $\begin{array}{l}\text { i.e. 'a shirt and a paint' But it is a culturally } \\
\text { significant outfit for which no exact equivalent is } \\
\text { available in English. (Pushpa 2005: 292-306 } \\
\text { trans.). }\end{array}$ \\
\hline
\end{tabular}

Similarly different clothing items such as salwar-suit, lahanga, phariya, dhoti (worn by both men and women in different forms), odhni (Pushpa 2015: 292-306) etc. can be rendered in English by adopting particular translation strategies in the given context to communicate competently without which these peculiarities would be difficult to find justification in the TT.

\section{Compound Words and Reduplicated Forms of SL}

However, compounding and reduplicated forms in the Indian languages follow a systematic and morpho-phonological pattern and make a language richer, but they also remain culture and context specific. When it comes to translation, semantic translation or closest possible equivalents, sometimes, do not suffice the purpose in the TL text. Sapir (1921: 76) in his book Language considers the prevalent of such language items a natural phenomenon, and notes that they are "generally employed, with self-evident symbolism, to indicate such concepts as distribution, plurality, repetition, customary activity, increase of size, added intensity, continuance...". To make it clearer, let us take a simple example of compound from Hindi chote-mote which can be 
better translated as 'meager' than 'small-big/fat'. In the story "Lalmaniyan" (Pushpa 2015: 292-306) a number of compounds and reduplicated patterns have been used and are contextual and creative too. For example:

\begin{tabular}{|l|l|}
\hline SL Text Item/s & Meaning \\
\hline Daan-dahej & 'dowry' instead of donation and dowry \\
\hline Jaat-biraadari & ' fraternity 'instead of 'caste and community' \\
\hline Dvaar-darvaaze & 'doorstep' instead of 'door and doors' \\
\hline Tonay-totkay & 'black magic' instead of 'superstitions and sorcery' \\
\hline Sugadh-salone & 'well adorned' instead of 'robust and pretty' \\
\hline Khaate-peete & 'wealthy' instead of 'well eaten and drank' \\
\hline Dhool-dhankar & 'dusty' instead of 'full of dust and soiled' \\
\hline Dhol-manjeere & $\begin{array}{l}\text { Specific music played on certain occasions } \\
\text { instead of 'percussion' }\end{array}$ \\
\hline Rudhi-rivaaz & 'customs' instead of 'traditions and orthodox' \\
\hline Chouki-peetha & 'threshold' (contextual in different situations) \\
\hline Kushal-khair & 'well being' instead of 'fine whereabouts' \\
\hline Shaan-shoukat & 'luxury' instead of 'grandeur and splandour' \\
\hline Aath-das & 'many' instead of eight-ten \\
\hline Jog-tap & 'hard work' (contextual in different situations) \\
\hline Baap-kaakaon & 'elders' instead of 'father and uncle' \\
\hline Naate-rishtedaar & 'relatives' instead of 'relatives and relatives' \\
\hline Heel-hulas & 'gusto' instead of 'move and enthusiasm' \\
\hline $\begin{array}{l}\text { Dho-dhokar } \\
\text { 'by washing' instead of 'washed-washing' } \\
\text { (Pushpa 2015: 292-306 trans.) }\end{array}$ \\
\hline $\begin{array}{l}\text { Sabakte-subakte } \\
\text { Badi-badi aankhe } \\
\text { Dare-dare se }\end{array}$ & $\begin{array}{l}\text { Flow of tears sobbing to look at something } \\
\text { astonished (total reduplication) } \\
\text { (Pushpa 2015: 31-49 trans.). } \\
\text { "Tum Kiski Ho Binni" }\end{array}$ \\
\hline
\end{tabular}

Such reduplicated and compound words, in translation, may take the influence of the mother tongue. Therefore, the linguistic difference between the ST and TT must not be confused with the direct meaning of these individual reduplicated forms and compound words. They perform certain function in the text and hence contain some concrete meaning that needs to come out of the cultural nuance of ST 
and its given context into the target language culture. Abbi (2001: 166) considers the same and explains, "reduplicated structures may be used to convey emphasis, accentuation and distributiveness, iconically. But in some Indian languages it may also be used to convey exclusiveness".

\section{Regional Vocabulary of Local Rituals and Food Items}

In an Indian literary text, dialectal peculiarities to represent local culture and its ritualistic traditions are obvious to take place; they need translational decisions and are crucial as well. In the stories of Maitreyi Pushpa, the regional vocabulary has been used at its best to give the rustic touch to the theme/s. At the lexical level words like, pathanwara (Pushpa 2015: 527), tharkuliya (Pushpa 2015: 297), maanikh, meda banana (Pushpa 2015: 301), bhayte ki garmi (a place, earthen pot, human being, to infatuate, extreme hot scorching weather respectively (trans.) are deeply contextual, culturally intact and certainly give a regional touch to the story. However, the absence of the exact equivalents does not hinder the translation process rather it needs to work out on additional levels. Firstly, to decode the lexical items in the given context and, then, its correct rendering in the TL culture that can be unambiguously comprehensible on the other level. As R. S. Pathak also considers:

The translator therefore has to bear in mind that there are no exact synonyms even in the same language and its dialects and that a language is not merely a medium through which experience is communicated but is something inseparable from the experience it communicates. Being a unique way of looking at undifferentiated reality, it invests its words with particular nuances (1996: 23).

Food items like maheri, jalebi, puri-saag, laddu, paan ka beeda (Pushpa 2015: 292-306) cannot be sensibly translated 
into English. The task of translation becomes even more troublesome when marriage rituals like barothi chaar-dwaar, Aipen ki ghodi pujna (Pushpa 2015: 304) and the like ask for translational choices or strategy. At such juncture "foreignization" of L. Venuti can mislead the TL reader and hence what Mona Baker (2011: 80) suggests "paraphrasing" resolves the issue.

Barothi chaar-dwaar (A ritual when the groom comes at the bride's doorstep), Aipen ki ghodi pujna (A newly-wedded bride is welcomed by performing the traditional rituals) (trans.).

The translation of dialectally registered terms like mandap, bandanvaar (Pushpa 2015: 303) in "Lalmaniyan" also resolved by the same approach. Although theorized upon the approaches, behind the text it is the rigorous analysis of a translator that can make these rituals flow naturally in the TT as Steiner (1975) observes in After Babel: Aspects of Language and Translation that language is a science and translation is an art. The art lies in assessing the type of translation required by the piece, the right kind of strategies to be selected and integrated in the right proportion.

Whatever approach one might follow in translation, when it comes to the regional text that imbibes certain grim realities of the rural vicinity, as in the case of the stories of Maitreyi Pushpa, the stories represent Indian feminism, the cultural barriers in translation opens new moot points and contributes to the field of Translation Studies. At this point the possibilities and correctness should be sought for rather rationalizing the question of appropriateness of being 'right' or 'wrong'. In this regard "On Auchitya of Translation and Translational Perspective”, Avadhesh Kumar Singh (1996: xv) rightly points out "translation is an endeavour to solve our obtaining problems and has to begin with the reception and the 
then response of the writer when s/he wrote". He adds to the question of appropriateness, "Propriety of translational act demands that translators should put the source-author's views in proper perspective to do justice to the source texts dealing with ultra-sensitive issues like religion, language and culture".

\section{Conclusion}

The practice of translation helps to widespread the dialectal, cultural and regional underpinning of the regional language literature through translations. At the same time, it relieves the socio-cultural concerns out of the notion of untranslatability by allowing to devise new methods both creative as well as critical. Along with, adding to the corpus of the Indian texts into English translation, the ideologies like 'feminism' represented through Indian texts find recognition across the globe and an Indian perspective of feminism unfolds through its circulation. The excessive focus on the anxiety of appropriateness, both in the process and in the product of translations, should shift towards the justifying principles for textual as well as contextual situations in hand.

\section{References}

ABBI, ANVITA. 2001. A Manual of Linguistic Field Work and Structures of Indian Languages. Munich:

LINCOM Europa.

BAKER, MonA. 2011. In Other Words: A Course Book on Translation. London and New York: Routledge.

BOAS, FrANZ. 2013. Handbook of American Indian Languages. New York: Cambridge University Press.

IVIR, VLADIMIR. 1987. Procedures and Strategies for the Translation of Culture. In Gideon Toury (ed.), Translation Across Cultures. New Delhi: Bahri Publication.

Katan, David. 2004. Translating Cultures: An Introduction for Translators, Interpreters and Mediators. London and New York: St. Jerome Publishing. 
PRASAD, KASHI. 1982. Some Problems of Translation from Indian Languages. Indian Literature 25.

PushPA, MATREYI. 2015. Samagra Kahaniyaan: Ab Tak. New Delhi: Kitab Ghar Publication.

Rubel Paula G. and Abraham Rosman. 2003. Are Kinship Terminologies and Kinship Concepts Translatable? In Paula G. Rubel and Abraham Rosman (eds.), Translating Cultures: Perspectives on Translation and Anthropology. New York: Berg Publishers.

SAPIR, EDWARD. 1921. Language. USA: Harcourt, Brace and World.

Senft, Gunter; Jan Ola Ostman; and Jef Verschueren (eds.). 2009. Culture and Language Use. Amsterdam: John Benjamins Publishing Company.

Singh, AvadHesh K. 1996. On Auchiyta of Translation and Transnational Perspective. Translation: Its Theory and Practice. New Delhi: Creative Books.

SteINER, GeORGe. 1975. After Babel: Aspects of Language and Translation. London: OUP.

$* * *$

Cite this work:

Kumawat, Deepa and Anjana, B. K. 2020. Dialectal Peculiarities of Indian Text and Context in Translation Practice: A Critique. Translation Today, Vol. 14(1). 23-34. DOI: 10.46623/tt/2020.14.1.ar2. 